\title{
Complete septate uterus with cervical duplication and longitudinal vaginal septum: an uncommon mullerian anomaly
}

\author{
Pundalik K. Sonawane*, Urvi C. Bhavsar
}

Department of Obstetrics \& Gynecology, K.J. Somaiya Medical College, Mumbai, Maharashtra, India

Received: 17 September 2015

Received: 20 September 2015

Accepted: 29 October 2015

\section{*Correspondence:}

Dr. Pundalik K. Sonawane,

E-mail: drpundalik@gmail.com

Copyright: ( ) the author(s), publisher and licensee Medip Academy. This is an open-access article distributed under the terms of the Creative Commons Attribution Non-Commercial License, which permits unrestricted non-commercial use, distribution, and reproduction in any medium, provided the original work is properly cited.

\begin{abstract}
The most commonly reported mullerian duct anomalies are septate, arcuate, didelphys, unicornuate or hypoplastic uteri. Here we describe a presentation of unusual mullerian anomaly. We report a case of 31 year old nulliparous woman with primary infertility married since 5 years with history of excision of longitudinal vaginal septum 2 years back. Clinical examination revealed two cervix. On ultrasound, she was diagnosed with single fundus with 2 uterine cavities and double cervix with complete septum within. Diagnosis was confirmed with hysterosalpingogram and MRI showing no communication between the two uterine cavities. On combined laproscopy and hysteroscopy, the septum was excised above the level of cervix transforming into a single cavity uterus with free bilateral spillage of fallopian tubes, keeping the two cervix intact. This anomaly is inconsistent with generally accepted understanding of mullerian development but fits within alternative hypothesis. Establishing an accurate diagnosis is essential for planning treatment and management strategies.
\end{abstract}

Keywords: Mullerian anomaly, Infertility, Uterine septum, Double cervix

\section{INTRODUCTION}

The incidence of congenital mullerian anomalies in the general population is estimated to be $0.001-10 \%{ }^{1}$ Septate and arcuate uteri represent $75 \%$ of Mullerian abnormalities. ${ }^{2}$ Mullerian anomalies result from improper development and fusion of embryological mullerian ducts. Not all can be classically explained by theory of caudo - cranial fusion and canalisation. Complex anomalies involving uterine, cervical and vaginal duplication can be postulated by alternative theory of bidirectional and segmental fusion of mullerian duct.

Structural genital malformations may be associated with recurrent pregnancy loss, preterm labour, abnormal fetal presentation and infertility. We report the case of a woman with this rare anomaly. Our observation are discussed in the light of available literature concerning diagnosis and management of similar cases. ${ }^{3-7}$

\section{CASE REPORT}

A 31 year old nulligravida woman, married since 5 years came with complaints of primary infertility and dysmenorrhea, with past history of excision of longitudinal vaginal septum 2 years back.

On speculum examination, a single vaginal cavity was visualised with a band of excised longitudinal septum, with two cervical openings. On vaginal examination, it was found that the uterus was normal in size, with two separate cervical os and bilateral fornices were found to be clear (Figure 1).

On ultrasound, a single fundus with two uterine cavities with complete uterine septum was found, a double cervix with complete cervical septum and the ovaries were bilaterally normal. 


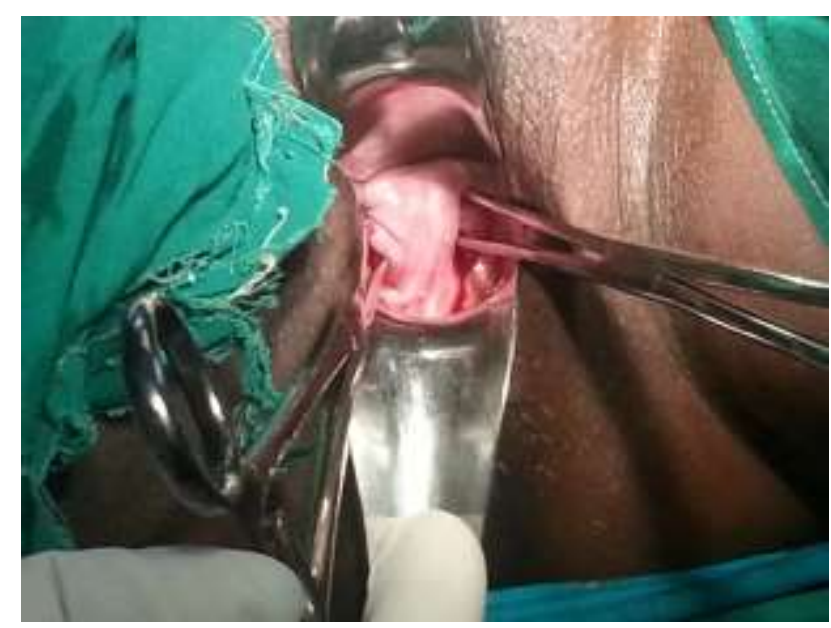

Figure 1: Speculum exainatiom: two cervices held with volsellum with cut longitudinal vaginal septum in between.

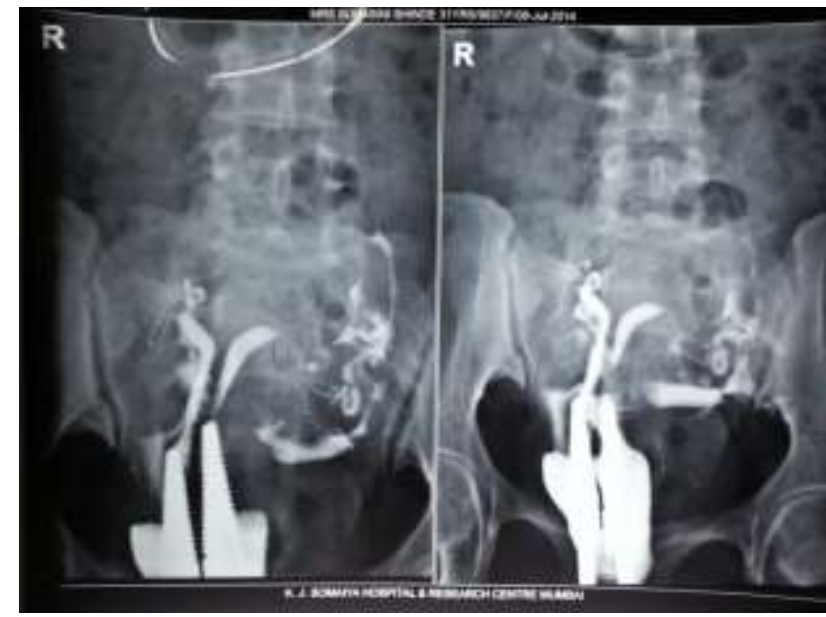

Figure 2: Hysterosalphingogram: Two uterine cavities with complete uterine septum continuous in cervical canal with bilateral free spill.

On hysterosalpingogram, two noncommunicating uterine cavities with double cervix were seen with bilateral free spillage of fallopian tubes (Figure 2).

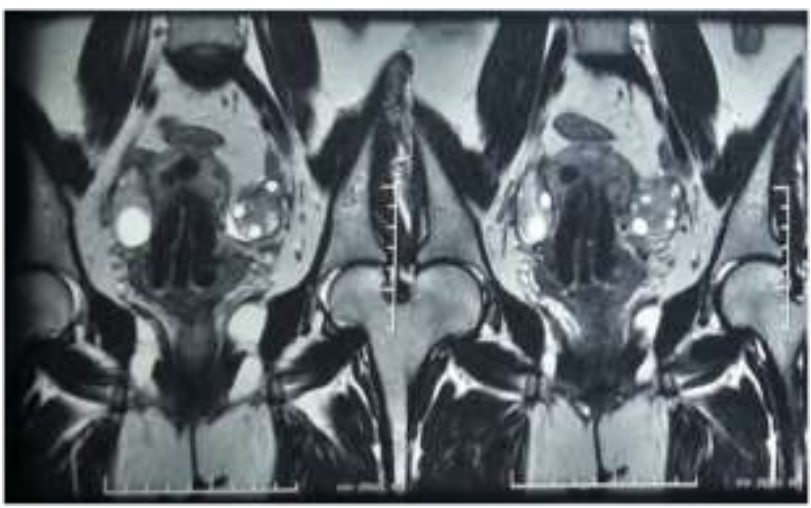

Figure 3: MRI: Single fundus with two uterine cavities and two cervical canals.
On MRI, a single fundus was found, two separate uterine cavities with complete uterine septum, continous with complete cervical septum, leading to double cervix, with no abnormalities in the urinary tract (Figure 3 ).

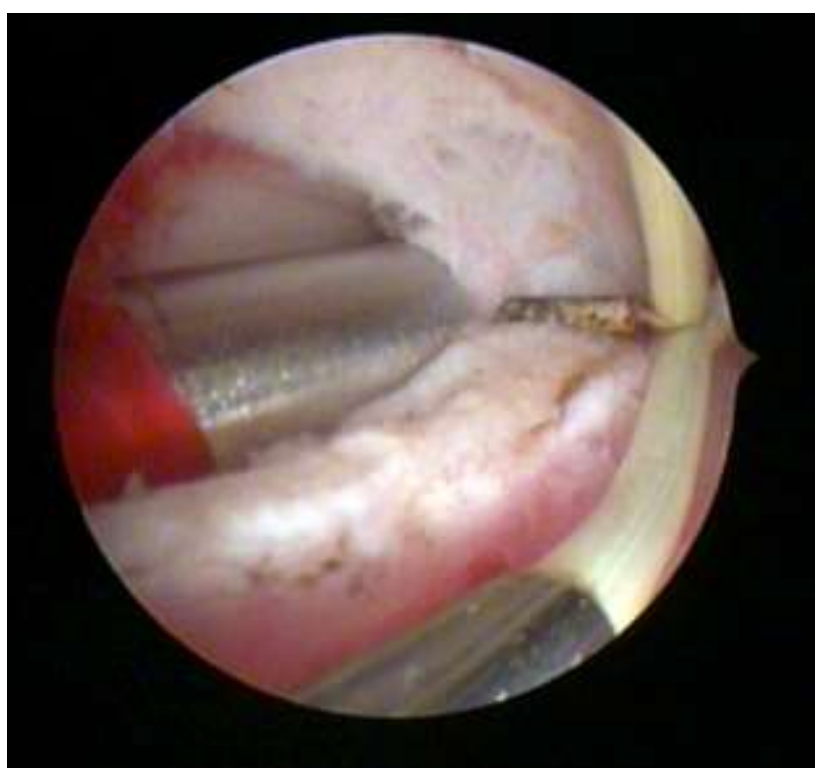

Figure 4: Hysteroscopic septum resection with metal dilator in other cavity.

On laparoscopy, a single fundus of uteri with normal adnexa was seen. On hysteroscopy, two uterine cavities with a thick complete septum from fundus downwards continous through cervical canal upto external os with two cervix was noted. Metal dilator was kept in one of the uterine cavity to distend or indent the septum. This uterine septum was completely excised with resectoscope above the level of internal os of cervix transforming into single uterine cavity with double cervix. Cervical unification was not done. On chromopertubation, free spillage was seen from bilateral tubes (Figure 4).

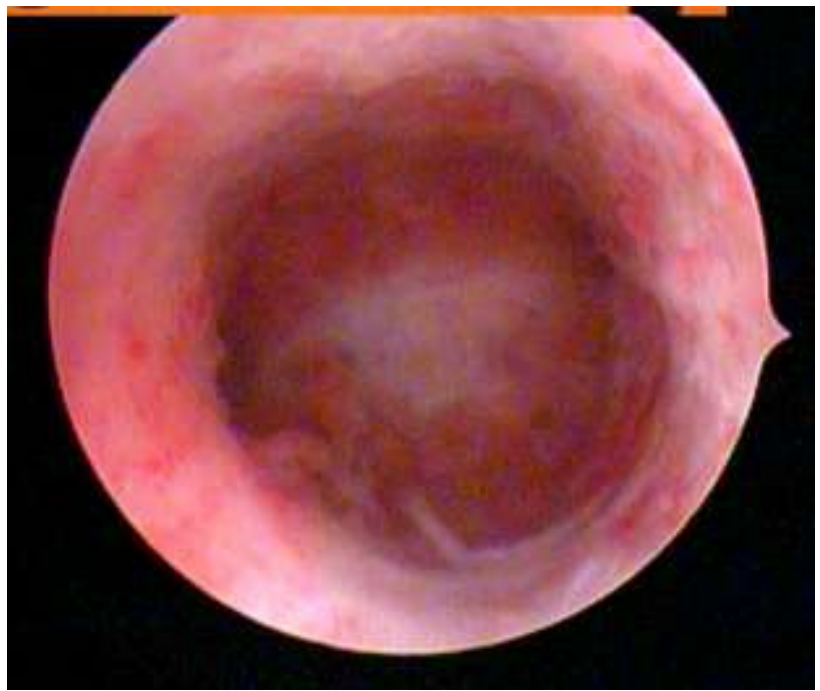

Figure 5: Post operative single uterine cavity. 
Postoperative recovery was uneventful. Paediatric Foley's catheter was kept in uterine cavity for 5 days. Cyclical oral contraceptive pills were given for 2 months. Hysteroscopy was performed 2 months later revealed a normal uterine cavity with two cervical canals (Figure 5).

\section{DISCUSSION}

Septate uterus with cervical duplication, with a longitudinal vaginal septum is a rare and unusual congenital malformation not fitting into commonly used classification of mullerian anomaly. ${ }^{8}$ Classical theory of uterine development as described by Crosby and Hill in 1962 resulted from the fusion of mullerian ducts beginining at the caudal most aspect and proceeding in cranial direction. ${ }^{9}$ Septal resorption was thought to follow, beginning at any point of fusion, in either direction leading to a unified uterine cavity. ${ }^{10}$

The case reported here cannot be explained by this theory, because a dual vagina/cervix complex suggests failure of caudal fusion while a septate uterus indicates normal cephalad fusion with failure of septal resorption. This case fits into an alternate theory, proposed by Musses in 1967 where uterus and cervix and upper vagina develop by three stage process, in which medial aspects of the mullerian ducts begin to fuse in the middle and proceed both caudad and cephalad directions simultaneously. ${ }^{9}$ According to this theory, the dual cervix could be explained by failed fusion of the mullerian ducts in the caudal direction beginning at uterine isthmus. The septate uterus and vagina could be explained by complete failure of normal septal resorption following normal fusion. This case can be easily confused with uterine didelphys.

Patton et al have identified and treated a total 16 cases representing one of the largest reported series till date. ${ }^{11}$ Saygili et al reported 9 cases which suggest that this atypical septate uterus is probably more frequent than reported. $^{12}$

Best approach to management to this anomaly is controversial. Resection of vaginal septum is easy and commonly performed. Hysteroscopic resection of septum is the gold standard to improve obstetric outcome. ${ }^{11,6}$ Various materials like metal or plastic dilator, foley's balloon $^{13}$ used to distend or indent the septum for resection. We used metal dilator in the other cavity and septum is resected above the level of internal os.

Unification of cervix by resecting cervical septum is also controversial. In our case, the cervical portion of septum (i.e fused medial junction of double cervix) was conserved because of concerned for problematic bleeding and future cervical incompetence. Patton et al and Üstün $\mathrm{Y}$ et al also spared the cervical unification in their management. $^{11,13}$
Our patient has not conceived yet, if conceives, elective caesarean section at term will be the mode of delivery.

\section{CONCLUSIONS}

The presence of this unusual anomaly provides information for understanding of embryology. Detailed preoperative investigation and meticulous planned surgery, gives desired outcome. Hysteroscopic resection of uterine septum using a minimally invasive approach is the gold standard treatment. Cervical manipulation increases the risk of incompetence; hence unification of two cervices remains controversial.

\section{Funding: No funding sources \\ Conflict of interest: None declared \\ Ethical approval: Not Required}

\section{REFERENCES}

1. McBean J, Brumsted JR. Septate uterus with cervical duplication: a rare malformation. Fertil Steril. 1994;62(2):415-7.

2. Acien P. Incidence of Mullerian defects in fertile and infertile women. Hum Reprod. 1997;12:1372-6.

3. Chang AS, Siegel CL, Moley KH, Ratts VS, Odem RR. Septate uterus with cervical duplication and longitudinal vaginal septum: a report of five new cases. Fertil Steril. 2004;81(4):1133-6.

4. Balasch J, Moreno E, Martinez-Román S, Moliní JL, Torné A, Sánchez-Martín F, et al. Septate uterus with cervical duplication and longitudinal vaginal septum: a report of three new cases. Eur J Obstet Gynecol Reprod Biol. 1996;65(2):241-3.

5. Sharara FI. Complete uterine septum with cervical duplication, longitudinal vaginal septum and duplication of a renal collecting system. A case report. J Reprod Med. 1998;43(12):1055-9.

6. Giraldo JL, Habana A, Duleba AJ, Dokras A. Septate uterus associated with cervical duplication and vaginal septum. J Am Assoc Gynecol Laparosc. 2000;7(2):277-9.

7. Ribeiro S, Yamakami L, Tormena RA. Septate uterus with cervical duplication with longitudinal vaginal septum. Rev. Asso Med Bras. 2010;56(2):254-6.

8. Buttram VC, Gibbons WE. Müllerian anomalies: A proposed classification (an analysis of 144 cases). Fertil Steril. 1979;32:40-6.

9. Musset R, Muller P, Netter A, Solal R, Vinourd JC, Gillet JY. Etat du haut appareil urinaire chez les porteuses de malformations uterines. Etude de 133 observations. Presse Med. 1967;75(26):1227-32.

10. Ergun A, Pabuccu R, Atayv, Kycuk T, Duru NK. Three sisters with septate uteri: another reference to bidirectional theory. Hum Reprod. 1997;12(1):140-2.

11. Patton PE, Novy MJ, Lee DM, Hickok LR. The diagnosis and reproductive outcome after surgical treatment of the complete septate uterus, duplicated 
cervix and vaginal septum. Am J Obstet Gynecol. 2004;190(6):1669-75.

12. Saygili-Yilmaz ES, Erman-Akar M, Bayar D, Yuksel B, Yilmaz Z. Septate uterus with a double cervix and longitudinal vaginal septum. J Reprod Med. 2004;49(10):833-6.

13. Üstün Y, Engin Üstün Y, Meydanii MM, Atmaca R, Kafkasli A. Hysteroscopic ballon technique for correction of complete uterine septum. J TurkishGerman Gynecol Assoc. 2006:229-31.

Cite this article as: Sonawane PK, Bhavsar UC. Complete septate uterus with cervical duplication and longitudinal vaginal septum: an uncommon mullerian anomaly. Int J Reprod Contracept Obstet Gynecol 2015;4:2065-8. 